\title{
School Cheating and Social Capital *
}

\author{
Marco Paccagnella \\ Paolo Sestito \\ Bank of Italy \\ Bank of Italy and Invalsi
}

\section{PRELIMINARY AND PARTLY INCOMPLETE DRAFT}

First Draft: February 2013

Current version: March, 2013

\begin{abstract}
In this paper we investigate the correlation between cheating in school tests and social capital in the context of Italian standardized tests administered by Invalsi. Given that such tests are low-stakes, we find natural to interpret the strong opposition showed by teachers and students (sometimes resulting in explicit boycotting of the tests) as signs of low trust towards the central education authority. Indeed, we find a robust negative correlation between cheating and social capital. We also confirm previous results that have documented that: (i) the presence of an external examiner strongly reduces cheating (Bertoni, Brunello, and Rocco, 2012); and (ii) in less homogeneus classes cheating is more difficult (Bertoni, Brunello, and Rocco, 2012; Lucifora and Tonello, 2012). Furthermore, we show that cheating is instead positively correlated with measures of particularistic social values: such measures (as opposed to universalistic social values) are signs of strong and close links that end up facilitating collusive behaviours.
\end{abstract}

Keywords: Cheating, Social Capital

JEL Codes: I28, D73, Z10

${ }^{*}$ We would like to thank Patrizia Falzetti, Giuseppe Albanese, Claudio Rossetti and Diego Scalise for generous help with the data. We are indebted to Rosario Ballatore, Marco Bertoni, Alessio D'Ignazio, Giovanna Labartino, and seminar participants at the Bank of Italy and Invalsi for valuable comments. The views expressed in this paper are solely those of the authors and do not involve the responsibility of Invalsi or the Bank of Italy. The usual disclaimer applies. Corresponding author: Marco Paccagnella, Bank of Italy, Trento Branch. P.zza A. Vittoria, 6. 38122 Trento. Email: marco.paccagnella@bancaditalia.it 


\section{Introduction}

A vast literature in economics and sociology has documented the relationship between social capital and social and economic outcomes. The positive link between social capital and economic growth (Algan and Cahuc, 2010; Knack and Keefer, 1997) is likely to operate through a better functioning of society's institutions (broadly defined). Following Banfield (1958), who argued that the backwardness of Southern Italy could be explained by the inability of selfinterested and family-centric inhabitants to cooperate for the common good, Putnam (1993) showed that Italian regions with higher active participation also displayed better local governments' performances, while Fukuyama (1995) further argued that high trust among citizens leads to superior performance of all institutions in a society, including firms. Indeed, the range of institutions and socioeconomic outcomes influenced by social capital is very broad: from financial development (Guiso, Sapienza, and Zingales, 2004) to trade (Guiso, Sapienza, and Zingales, 2009), from firms' size and organization (La Porta, Lopez-de-Silanes, Shleifer, and Vishny, 1997) to state intervention and regulation (Aghion, Algan, Cahuc, and Shleifer, 2010, Djankov, Glaeser, La Porta, Lopez-de Silanes, and Shleifer, 2003; Pinotti, 2009, 2012), from public good provision (Giordano and Tommasino, 2011; Putnam, 1993) to political accountability (Nannicini, Stella, Tabellini, and Troiano, forthcoming).

In this paper, we investigate the link between social capital and the school system. School is a very peculiar institution, not only because of its obvious importance in terms of human capital formation, but also because of its role in the transmission of values, norms and beliefs. Indeed, although family has traditionally been seen as the main channel for social capital transmission (Bisin and Verdier, 2001; Guiso, Sapienza, and Zingales, 2007; Tabellini, 2008), more recent studies have highlighted the importance of schools (Aghion, Algan, Cahuc, and Shleifer. 2010; Algan, Cahuc, and Shleifer, forthcoming; Glaeser, Ponzetto, and Shleifer, 2007; Guiso, Sapienza, and Zingales, 2010, Helliwell and Putnam, 2007, Milligan, Moretti, and Oreopoulos, 2004).

In particular, we use data from the 2009/10 wave of the Italian National Survey of Students' Assessment (SNV), an evaluation of students' achievements and school quality, conducted on an annual basis by the National Institute for the Evaluation of the Education System (Invalsi, from now on). The SNV is a standardized test administered to all Italian students enrolled in second and fifth grades (primary schools) and in sixth and eigth grades (junior high-school), covering Mathematics and Italian Language. Such tests were introduced with the explicit purpose of evaluating school quality. However, they cannot be defined high-stakes: neither the allocation of resources to schools, nor teachers' salary, nor students' career depend on test results $^{1}$. Still, from the very beginning they have met strong opposition from the actors involved. Teachers and schools' principals, probably afraid of the future use of such instruments for eval-

\footnotetext{
${ }^{1}$ Eight graders are an exception: the test is administered in the context of their final junior-high school exams and partly contribute to the determination of their final mark.
} 
uation purposes, were the first to strongly criticize such tests, arguing they were not able to capture "true" student learning (hence, they were not fit to measure quality of teaching), but opposition soon came from students and parents as well. According to anecdotal evidence, sometimes opposition took the form of explicit attempts to boycott the tests, with teachers openly encouraging students to stay home, or letting them cooperate, or suggesting answers to the entire class. In some other cases, pressure to perform well in the tests was high because of the expectation that results could be eventually used to evaluate schools and teachers, and because schools' reputation was perceived to be at stakes. For whatever reasons, cheating was common, whether it came from the students or induced by the teachers; for this reason, Invalsi routinely "adjusts" test scores using a procedure developed by Castellano, Quintano, and Longobardi (2009). Three recent studies investigate the extent, the causes and consequences of cheating bias using our very same data. Ferrer-Esteban (2012) proposes an alternative method to identify cheating behaviour and compares it to the one used by Invalsi; Bertoni, Brunello, and Rocco (2012) show that having an external examiner (sent by Invalsi to randomly selected schools) administering the test significantly reduces average test scores, presumably by strongly reducing cheating behaviour; Lucifora and Tonello (2012) estimate a structural model of social interactions to compute a "social multiplier" for cheating.

In this paper we look at cheating behaviour from a different perspectives. Given the context described above (low-stakes test), we interpret the opposition to the test (and, consequently, cheating behaviour) as a sign of low trust towards the centralized authority administering the tests. Teachers' and students' aversion to the test was mainly motivated by fear that test results could be somehow misused by Invalsi ${ }^{2}$. From this perspective, it is natural to link cheating behaviour and social capital. The main purpose of the paper is thus to show that cheating behaviour is indeed (negatively) correlated with social capital, as measured by a number of traditional proxies routinely used in the literature. Our work is thus related to Durante, Labartino, and Perotti (2011) who show how social capital can enhance accountability and efficiency of higher education institutions.

Compared to traditional measures of social capital, cheating has two advantages. First, it measures actual behaviour rather than (as often done) values or beliefs reported by survey respondents (thus avoiding the risk of social desirability bias). Second, it is a measure available with high frequency and at a very disaggregated geographical level, which in principle could allow researchers to better study the evolution of social capital over time (or over cohorts). As a by-product, we are able to document some interesting determinants of cheating behaviour, mainly confirming the results of the above mentioned studies.

The rest of the paper is organized as follows. In Section 2 we describe in more detail the institutional setting and the various data sources used in the study. In Section 3 we describe the empirical model and present the main estimation results. In Section 4 we perform some robustness checks and extend our main results by showing how results depend on the chosen

\footnotetext{
${ }^{2}$ Notwithstanding the many attempts Invalsi undertook to open a dialogue with the actors involved.
} 
definition of social capital, focusing in particular on the comparison between universalistic and particularistic social values (De Blasio, Scalise, and Sestito, 2013). Section 5 concludes.

\section{Data and Institutional Setting}

\subsection{Invalsi Survey of Students' Assessment}

The main data source, as we already explained in the Introduction, is the 2009/10 wave of the National Survey of Students' Assessment (SNV) conducted by Invalsi. The available data contain information on the individual answers to each item of the tests administered to $2 \mathrm{nd}$, 5th, 6th and 8th graders. Tests in Mathematics and the Italian Language took place in late May, in two different days. Test administration and marking was carried out by school teachers, who should (in principle) follow a strict Protocol set by Invalsi (see Invalsi (2010a b) for more details). The test was not to be administered by the class teacher herself, but by a different teacher (of the same school) specialized in a different subject; marking was to be jointly done by all school teachers simultaneously, with the school principal supervising the entire process. The Protocol also entails the use of external inspectors, sent to a randomly selected sample of classes, with the goal to invigilate students during the test, provide information and support on the test administration, compute test scores and send back results and documentation to Invalsi ${ }^{3}$. Other than test scores, the data contain a number of informations on students' socio-economic characteristics, like gender, citizenship (italian, 1st generation immigrant, 2nd generation immigrant), parental occupation and education, school mid-year marks. For 5th and 6th graders, an index of economic social and cultural status (ESCS) is computed, by aggregating information on parental education, parental wealth and home educational resources. With the excetpion of 8th graders (who sit the test in the context of their final junior-high school exams, with the test partly contributing to the determination of their junior-high school leaving mark), the test is low-stakes for all students, since it does not affect in any way their school career. Given the peculiarity of 8th graders, and the fact that for 2nd graders we lack information on students' ESCS, we will focus the empirical analysis to 5th and 6th graders. The last (and crucial) piece of information contained in the database is a measure of cheating. Such measure is computed by Invalsi, following the statistical procedure proposed by Castellano, Quintano, and Longobardi (2009). In a nutshell, the procedure tries to identify "suspicious" classes, i.e. classes characterized by low within variability of scores, homogeneous answers behaviour and low percentage of missing answers. The procedure delivers a weighting factor, an (inverse) measure of cheating probability, $w_{j} \in[0,1]$. This index is then used by Invalsi to adjust the average score of class $j$ : if a class is identified as very suspicious, it will receive a very low weight. In the empirical analysis we will use $c_{j}=1-w_{j}$ as a class-level measure of cheating

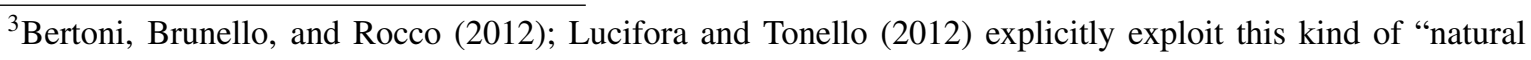
experiment" in their papers 
intensity. Basic descriptive statistics of our data are displayed in Table 1 .

[INSERT TABLE[1]ABOUT HERE]

\subsection{Social Capital}

Given that the main purpose of the paper is to "validate" school cheating as a proxy for social capital, we use a number of traditional measures. In the attempt to exploit the very thin geographical disaggregation of the Invalsi data, for our baseline estimates we proxy social capital using average turnover at national elections held from 1946 to 2008. This is the only variable which is available at the level of municipalities ${ }^{4}$. For robustness reasons we also use a number of other measures, routinely used in the vast literature that has studied issues of social capital in the Italian context: electoral turnover at referenda (and at the 1974 referendum on divorce, in particular), blood donations and a measure of trust from the World Value Surveys (see Guiso, Sapienza, and Zingales 2004, among others). However, we recognize that social capital is a rather vague concept. Although widely studied in the social sciences, it is not rare that different authors and different disciplines have in mind different definitions of this concept. Sestito (2011) tries to summarize the debate on this issue by identifying two extreme views. On the one hand, social capital can be seen as "civicness" (a set of values, norms and beliefs able to facilitate cooperation among individuals); on the other hand, it can be measured as the density of social networks an individual belongs to (with this latter interpretation lacking, ex-ante, any ethical or moral characterization). We believe that a crucial feature of both concepts lies in the degree of particularism or universalism - of norms and values as well as of active participation in social, political or family networks. De Blasio, Scalise, and Sestito (2013) folllow this route and, using Italian microdata from 2010, compute some proxies for the degree of particularism (generalism) across different dimensions of social capital - namely trust, civic awareness and participation into associations. We use the same methodology to compute proxies for universalistic and particularistic social capital using the 2009 wave of the Multipurpose Survey on Italian Households, conducted by Istat. The 2009 wave allows us to construct measures at the provincial level, but lacks questions on trust; therefore, we have to limit ourselves to the dimensions of civic awareness and participation into associations. The basic way we build measures of particularistic social values is based on the use of the difference operator between the use of family and friends versus general mass media as a mean of acquire political information (civic awareness) and between participation in association centered around people of the same kind/type/social group versus participation in associations with more broadly defined goals and objectives (social participation). Measures of generalistic social values are constructed from different questions (to avoid spurious correlation) and identify social behaviours aimed at the good of the society as a whole, and not restricted to traditional social structures like family, kinship, neighbourhood, and so on.

\footnotetext{
${ }^{4}$ In Italy there are currently 8092 municipalities, 110 provinces and 20 regions.
} 


\section{Empirical Results}

In this section we present our baseline results documenting a negative association between cheating and social capital. As explained in section 2.1. we focus on 5th and 6th graders, for which we have the most complete set of information and for which the test was low-stakes.

Exploiting the fact that the same classes take two different tests in Italian Language and Mathematics, we estimate the following system of seemingly unrelated regressions (SUR $)^{5}$ :

$$
c_{j m}=\alpha+\beta T U R N_{m}+\gamma X_{j}+\varphi C_{m}+\epsilon_{j}
$$

where $c_{j m}$ is a measure of cheating in class $j$ in municipality $m, T U R N_{m}$ is electoral turnover in municipality $m, X_{j}$ and $C_{m}$ are, respectively, vectors of controls at the class and municipality levels. The system is made up of two equations, one for Mathematics and one for Italian Language. Standard errors are clustered at the municipality level and observations are weighted by class size.

The variables in the vector $C_{m}$ are rather standard and include municipalities' characteristics like population, area, elevation,share of females, share of inhabitants below 15 years and above 65 , dummies for whether the municipality is the regional capital and for whether it lies on the seaside.

The variables in the vector $X_{j}$ are measured at the class level and deserve a few comments, before jumping to the results.

The first obvious controls are dummies for whether an external examiner was present in the class or in the school. Bertoni, Brunello, and Rocco (2012) showed, in fact, that the presence of an external observer is an effective way to reduce cheating not only in the monitored class, but also in other classes of the same school.

Second, we would like to control for class composition and students' characteristics. The relevant dimension to look at, in this context, is class heterogeneity. Lucifora and Tonello (2012) stressed the importance of social interactions and argued that spillover effects are larger in classes more homogeneus in terms of social ties and socio-economic background. For this reason we include in the regression two indices of fractionalization, related to immigrant status (italian, first and second generation immigrants) and (quartiles of) $\mathrm{ESCS}^{6}$. It is reasonable to assume that in more fractionalized classes cooperation among students is more difficult to realize. The fractionalization index is an easy to compute transformation of the Herfindal concentration index appplied to population shares, and measures the probability that two randomly drawn individuals from the overall population belong different groups (pre-defined, in our case, in terms of citizenship and socio-economic status; see Bossert, D'Ambrosio, and La Ferrara 2011

\footnotetext{
${ }^{5}$ We also tried two alternative specifications: separate regressions for each subject and pooled regression with a subject dummy. Unsurprisingly, the results do not change significantly, and are available from the authors upon request.

${ }^{6}$ We also tried to include fractionalization indexes based on father's education and occupation, obtaining similar results.
} 
and Vigdor 2002). Formally, the fractionalization index is computed as

$$
F(p)=1-\sum_{k=1}^{K} p_{k}^{2}
$$

where $p=\left(p_{1}, \ldots, p_{k}\right) \in \Delta^{K}$ are the population shares for $K$ pre-defined groups.

Another important dimension to look at, we believe, is past school performance and students' ability. The tricky aspect is that we do not have an independent measure of students' ability. Furthermore, school marks are assigned by class teachers, and are likely to be biased or inflated, and they are certainly not robustly comparable across different classes and schools. Our strategy is to rely on the random allocation of external examiners to obtain reliable measures of students' test scores. We compute predicted test scores as the fitted values of a regression (on the subsample of classes with external observer) of test scores on students' observable characteristics (gender, citizenship, ESCS). Then we standardize both such predictions and students' mid-year marks and we compute the difference between the two. This is meant to be a measure of students' over (or under) evaluation by teachers. Such measures can be relevant for cheating behaviour, since it is reasonable to think that teachers will have more incentives to help students with inflated school marks.

Our baseline results are reported in tables 2 and 3 , for 5 th and 6th graders respectively.

\section{[INSERT TABLE2ABOUT HERE]}

\section{[INSERT TABLE 3 ABOUT HERE]}

For 5th graders, the regression results robustly point towards a negative relationship between cheating behaviour and social capital. To give an idea of the magnitude of the effect, an increase in voter turnout of 1 percentage point (one fifth of a standard deviation) si associated with a reduction of $2.5 \%$ of a standard deviation in cheating. As expected, monitoring strongly reduces cheating behaviour, as well as the degree of fractionalization. On the contrary, classes in which school marks are higher (relative to test scores) tend to be more prone to cheating. For 6th graders results are less robust, and the evidence is a bit mixed, in particular with respect to Italian Language.

\section{Robustness and Extensions}

\subsection{Looking at 2nd and 8th graders}

The first robustness checks is to estimate equation 1 for 2 nd and 8 th graders. For 2 nd graders, the only piece of information we miss is ESCS. For 8th graders, we miss ESCS and school marks, and the test is high-stakes.

The results showed in tables 4 and 5 , however, lend further support to the idea that cheating behaviour is less prevalent in areas with higher social capital. 


\subsection{Teachers' characteristics and interaction effects}

In this subsection we extend the specification of equation 1 along two dimensions.

First, we try to control for teachers' characteristics. In particular, for a subsample of schools we were able to collect information (unfortunately, only available at the school level) on teachers' birthplace, with the idea that teachers born in different parts of the country share less linkages with students, and are thus less prone to help them cheat. Therefore, we estimate the following equation:

$$
c_{j m s}=\alpha+\beta T U R N_{m}+\gamma X_{j s}+\delta T_{s}+\varphi C_{m}+\epsilon_{j m s}
$$

where $T_{s}$ is the share of teachers in school $s$ born in a different italian macro-regions ${ }^{7}$.

Second, we try to look at interaction effects between monitoring and social capital, by estimating

$$
c_{j m}=\alpha+\beta T U R N_{m}+\delta M O N_{j}+\chi M O N_{j} * T U R N_{m}+\gamma X_{j}+\varphi C_{m}+\epsilon_{j}
$$

Results are presented in table 6. For ease of exposition (and to save space) we report results from a pooled regression, controlling for a subject dummy ${ }^{8}$

\section{[INSERT TABLE6ABOUT HERE]}

The odd columns show that, as expected, having a higher share of teachers born in a different macro-area lead to less cheating, presumably due to less cooperation between teachers and students. Even columns show that, in area with high social capital, the marginal gains from monitoring are much lower (or, alternatively, that social capital has little to no effect in monitored classes).

\subsection{Alternative measures of Social Capital}

An obvious robustness check is to put different measures of social capital in the regression. Alternative measures (routinely used in the literature) are only available at the provincial level.

Table 7 show, for 5 th graders only ${ }^{9}$, the results of a number of pooled regressions in which the following measures of social capital are employed: turnover at national elections, turnover

\footnotetext{
${ }^{7}$ Italy is often divided in four macro-regions: North-West, North-East, Center, South and Islands.

${ }^{8}$ Results using SUR or separate OLS regressions are available upon request.

${ }^{9}$ Results for other grades are quite consistent with what shown previously. The relationship is quite robust for 2nd graders and 8 th graders, less so for 6th graders. Results are available upon request.
} 
at referenda, turnover at the divorce referendum, blood donations, a measure of trust from the World Value Survey. Province-level controls include the previous variables used at the municipality level, the number of municipalities in the province and the unemployment rate in 2009. The empirical results lend support to the thesis that cheating and social capital are negatively correlated.

\section{[INSERT TABLE[7]ABOUT HERE]}

\subsection{Universalistic vs. Particularistic Social Values}

Our final empirical exercise looks at possible differential effects of universalistic and particularistic social values, building on the measures estimated by De Blasio, Scalise, and Sestito (2013), as explained in Section 2.2.

Table 8 shows, again, the results of a number of pooled regressions, restricting attention to 5th graders. Coherently with our hypothesis, universalistic social values are negatively correlated with cheating, while particularistic social values are a sign of strong cooperative behaviour, but more of the type of the 'amoral familism' (Banfield, 1958), and are positively correlated with cheating.

\section{[INSERT TABLE[8ABOUT HERE]}

\section{Conclusions}

In this paper we have contributed to the rapidly growing literature that, starting from the original contribution of Jacob and Levitt (2003), analyzes cheating behaviour in standardized tests; in particular, a number of papers has investigated the Italian context, given the recent availability of very rich data on the subject (Bertoni, Brunello, and Rocco, 2012; Ferrer-Esteban, 2012; Lucifora and Tonello, 2012; Newman, 2012). Our contribution consists in linking such behaviour to more traditional measures of social capital. The Italian case is an interesting one. Standardized tests are (at the moment) low stakes, yielding no practical consequences on teachers' or students' careers; yet, they faced, from the very beginning, fierce opposition, that can be rationalized only as a sign of very low levels of trust towards the centralized authority responsible for the administration of such tests. We document a robust negative correlation between cheating and social capital, and we confirm results from previous studies that have investigated the determinants of cheating behaviour (in particular, we find that cheating is less common in more fractionalized classes, and it is more common in classes with higher grade inflation). Finally, we show that the relevant dimension of social capital to look at when analyzing cheating behaviour is related to universalistic social values. Particularistic social values, in fact, are a sign of too strong and close connections, by which cooperative behaviour degenerates into collusive behaviour; indeed, cheating is higher in areas with higher particularistic social values. 


\section{References}

Aghion, P., Y. Algan, P. Cahuc, And A. Shleifer (2010): "Regulation and Distrust," Quarterly Journal of Economics, 125(3), 1015-1049.

Algan, Y., And P. CAhuC (2010): "Inherited Trust and Growth," American Economic Review, 100(5), 2060-92.

Algan, Y., P. CAhuc, And A. ShleIfer (forthcoming): "Teaching Practices and Social Capital," American Economic Journal: Applied Economics.

BAnfield, E. C. (1958): The Moral Basis of a Backward Society. Free Press, New York.

Bertoni, M., G. Brunello, and L. Rocco (2012): "When the Cat Is Near, the Mice Won't Play: The Effect of External Examiners in Italian Schools," IZA Discussion Papers 6629, Institute for the Study of Labor (IZA).

Bisin, A., AND T. Verdier (2001): "The Economics of Cultural Transmission and the Dynamics of Preferences," Journal of Economic Theory, 97(2), 298-319.

Bossert, W., C. D’Ambrosio, and E. La Ferrara (2011): “A Generalized Index of Fractionalization," Economica, 78(312), 723-750.

Castellano, R., C. Quintano, and S. Longobardi (2009): “A Fuzzy Clustering Approach to Improve the Accuracy of Italian Student Data. An Experimental Procedure to Correct the Impact of the Outliers on Assessment Test Scores," Statistica \& Applicazioni, VII(2), $149-171$.

De Blasio, G., D. Scalise, and P. Sestito (2013): "Universalism vs. Particularism: A Roundtrip from Sociology to Economics," mimeo, Bank of Italy.

Djankov, S., E. Glaeser, R. La Porta, F. Lopez-de Silanes, and A. Shleifer (2003): "The New Comparative Economics," Journal of Comparative Economics, 31(4), 595-619.

Durante, R., G. Labartino, and R. Perotti (2011): “Academic Dynasties: Decentralization and Familism in the Italian Academia," NBER Working Papers 17572, National Bureau of Economic Research, Inc.

Ferrer-Esteban, G. (2012): "Cheating to the Test in the Italian Standardized Assessment System: Rationale and Incentives," Discussion paper, Fondazione Giovanni Agnelli.

FuKuYAma, F. (1995): Trust. Free Press, New York.

Giordano, R., And P. Tommasino (2011): "Public Sector Efficiency and Political Culture," Temi di discussione (Economic working papers) 786, Bank of Italy, Economic Research and International Relations Area.

Glaeser, E., G. Ponzetto, And A. Shleifer (2007): "Why Does Democracy Need Education?," Journal of Economic Growth, 12(2), 77-99.

Guiso, L., P. S APIEnZA, And L. Zingales (2004): “The Role of Social Capital in Financial Development," American Economic Review, 94(3), 526-556. 
(2007): “Social Capital as Good Culture,” NBER Working Papers 13712, National Bureau of Economic Research, Inc.

(2009): “Cultural Biases in Economic Exchange?," Quarterly Journal of Economics, 124(3), 1095-1131.

(2010): "Civic Capital as the Missing Link," NBER Working Papers 15845, National Bureau of Economic Research, Inc.

Helliwell, J. F., And R. D. Putnam (2007): "Education and Social Capital," Eastern Economic Journal, 33(1), 1-19.

INVALSI (2010a): “Esami di Stato Primo Ciclo - A.S. 2009/2010 - Prova Nazionale.,” .

(2010b): "Sistema Nazionale di Valutazione - A.S. 2009/2010 - Rilevazione degli Apprendimenti.," .

JACOB, B. A., And S. D. LevitT (2003): "Rotten Apples: An Investigation of the Prevalence and Predictors of Teacher Cheating," Quarterly Journal of Economics, 118(3), 843-877.

Knack, S., And P. Keefer (1997): "Does Social Capital Have an Economic Payoff? A Cross-Country Investigation," Quarterly Journal of Economics, 112(4), 1251-88.

La Porta, R., F. Lopez-De-Silanes, A. Shleifer, And R. W. Vishny (1997): “Trust in Large Organizations," American Economic Review, 87(2), 333-38.

LuCifora, C., And M. Tonello (2012): “Students' Cheating as a Social Interaction: Evidence from a Randomized Experiment in a National Evaluation Program," IZA Discussion Papers 6967, Institute for the Study of Labor (IZA).

Milligan, K., E. Moretti, And P. Oreopoulos (2004): "Does Education Improve Citizenship? Evidence from the United States and the United Kingdom," Journal of Public Economics, 88(9-10), 1667-1695.

Nannicini, T., A. Stella, G. Tabellini, and U. Troiano (forthcoming): "Social Capital and Political Accountability," American Economic Journal: Economic Policy.

Newman, L. (2012): "Fair Play, Social Trust and Development," mimeo, London School of Economics.

PinotTi, P. (2009): “Trust and Regulation: Addressing a Cultural Bias," Temi di discussione (Economic working papers) 721, Bank of Italy, Economic Research and International Relations Area.

(2012): "Trust, Regulation and Market Failures," Review of Economics and Statistics, 94(3), 650-658.

Putnam, R. D. (1993): Making Democracy Work. Princeton University Press, Princeton, NJ.

Sestito, P. (2011): “I diversi concetti di Capitale Sociale," in Il Capitale Sociale. Che cos'è e che cosa spiega, ed. by D. Editore, pp. 43-57. Donzelli Editore.

TABELlini, G. (2008): “The Scope of Cooperation: Values and Incentives," Quarterly Journal of Economics, 123(3), 905-950. 
VIGDOR, J. (2002): “Interpreting Ethnic Fragmentation Effects," Economics Letters, 75, 271276. 


\section{Tables}

Table 1: Students' Descriptive Statistics

\begin{tabular}{|c|c|c|c|c|c|c|c|c|}
\hline & \multicolumn{2}{|c|}{ 2nd grade } & \multicolumn{2}{|c|}{ 5th grade } & \multicolumn{2}{|c|}{ 6th grade } & \multicolumn{2}{|c|}{ 8th grade } \\
\hline & Italian & Mathematics & Italian & Mathematics & Italian & Mathematics & Italian & Mathematics \\
\hline Cheating & $\begin{array}{c}0.064 \\
(0.190)\end{array}$ & $\begin{array}{c}0.074 \\
(0.211)\end{array}$ & $\begin{array}{c}0.070 \\
(0.201)\end{array}$ & $\begin{array}{c}0.069 \\
(0.199)\end{array}$ & $\begin{array}{c}0.080 \\
(0.185)\end{array}$ & $\begin{array}{c}0.024 \\
(0.093)\end{array}$ & $\begin{array}{c}0.067 \\
(0.169)\end{array}$ & $\begin{array}{c}0.066 \\
(0.166)\end{array}$ \\
\hline School mark ${ }^{a}$ & $\begin{array}{c}7.78 \\
(0.618)\end{array}$ & $\begin{array}{c}7.90 \\
(0.618)\end{array}$ & $\begin{array}{c}7.46 \\
(0.597)\end{array}$ & $\begin{array}{c}7.56 \\
(0.593)\end{array}$ & $\begin{array}{c}6.54 \\
(0.591)\end{array}$ & $\begin{array}{c}6.61 \\
(0.636)\end{array}$ & - & - \\
\hline Raw test scores & $\begin{array}{c}65.73 \\
(13.00)\end{array}$ & $\begin{array}{c}62.61 \\
(14.13)\end{array}$ & $\begin{array}{c}69.84 \\
(10.31)\end{array}$ & $\begin{array}{c}64.89 \\
(12.27)\end{array}$ & $\begin{array}{l}60.85 \\
(7.41)\end{array}$ & $\begin{array}{l}51.47 \\
(9.11)\end{array}$ & $\begin{array}{l}64.65 \\
(8.79)\end{array}$ & $\begin{array}{c}55.66 \\
(10.36)\end{array}$ \\
\hline$\%$ Female & 49.073 & 49.026 & 49.346 & 49.280 & 48.330 & 48.336 & 49.319 & 49.339 \\
\hline$\%$ Italian & 90.893 & 90.816 & 91.036 & 90.942 & 90.027 & 90.014 & 92.813 & 92.838 \\
\hline No. Students & 492,687 & 488,672 & 498,382 & 491,421 & 520,841 & 520,759 & 499,905 & 498,884 \\
\hline No. schools & 7,558 & 7,554 & 7,542 & 7,541 & 5,825 & 5,824 & 5,733 & 5,734 \\
\hline No. classes & 29,527 & 29,502 & 29,830 & 29,811 & 26,725 & 26,716 & 25,923 & 25,923 \\
\hline Avg. Class size & \multicolumn{2}{|c|}{$\begin{array}{c}17.41 \\
(5.348)\end{array}$} & \multicolumn{2}{|c|}{$\begin{array}{c}17.24 \\
(5.435)\end{array}$} & \multicolumn{2}{|c|}{$\begin{array}{c}19.55 \\
(4.490)\end{array}$} & \multicolumn{2}{|c|}{$\begin{array}{c}19.33 \\
(4.530)\end{array}$} \\
\hline
\end{tabular}

${ }^{a}$ On a scale from 1 to 10. 
Table 2: Cheating and Social Capital - 5th graders

\begin{tabular}{|c|c|c|c|c|}
\hline & \multicolumn{2}{|c|}{$[1]$} & \multicolumn{2}{|c|}{$[2]$} \\
\hline & Italian & Mathematics & Italian & Mathematics \\
\hline Avg. turnover (1946-2008) & $\begin{array}{c}-0.007 * * * \\
{[0.000]}\end{array}$ & $\begin{array}{c}-0.008 * * * \\
{[0.000]}\end{array}$ & $\begin{array}{c}-0.005 * * * \\
{[0.000]}\end{array}$ & $\begin{array}{c}-0.006 * * * \\
{[0.000]}\end{array}$ \\
\hline School mark-Test Score ${ }^{a}$ & - & - & $\begin{array}{c}0.016 * * * \\
{[0.002]}\end{array}$ & $\begin{array}{c}0.018^{* * *} \\
{[0.002]}\end{array}$ \\
\hline Monitored Class & - & - & $\begin{array}{c}-0.026 * * * \\
{[0.004]}\end{array}$ & $\begin{array}{c}-0.024 * * * \\
{[0.004]}\end{array}$ \\
\hline Monitored School & - & - & $\begin{array}{c}-0.018 * * * \\
{[0.003]}\end{array}$ & $\begin{array}{c}-0.017 * * * \\
{[0.008]}\end{array}$ \\
\hline Ethnic Fractionalization & - & - & $\begin{array}{c}-0.073 * * * \\
{[0.008]}\end{array}$ & $\begin{array}{c}-0.071 * * * \\
{[0.008]}\end{array}$ \\
\hline ESCS Fractionalization & - & - & $\begin{array}{c}-0.044 * * * \\
{[0.007]}\end{array}$ & $\begin{array}{c}-0.032 * * * \\
{[0.007]}\end{array}$ \\
\hline Municipality characteristics & \multicolumn{2}{|c|}{ NO } & \multicolumn{2}{|c|}{ YES } \\
\hline $\begin{array}{l}\text { BP test of independence of residuals } \\
\text { Test b1 (ita)=b1 (math) }\end{array}$ & \multicolumn{2}{|c|}{$\begin{array}{l}\operatorname{Pr}=0.000 \\
\operatorname{Pr}=0.000\end{array}$} & \multicolumn{2}{|c|}{$\begin{array}{l}\operatorname{Pr}=0.000 \\
\operatorname{Pr}=0.000\end{array}$} \\
\hline R squared & 0.036 & 0.052 & 0.057 & 0.081 \\
\hline Observations $^{b}$ & \multicolumn{2}{|c|}{29,742} & \multicolumn{2}{|c|}{27,958} \\
\hline
\end{tabular}

Regressions weighted by the number of students in the class. Standard errors clustered at the municipal level

${ }^{a}$ Difference between standardized school mark and predicted test score

${ }^{b}$ The unit of observation is the class 
Table 3: Cheating and Social Capital - 6th graders

\begin{tabular}{|c|c|c|c|c|}
\hline & \multicolumn{2}{|r|}{$[1]$} & \multicolumn{2}{|c|}{$[2]$} \\
\hline & Italian & Mathematics & Italian & Mathematics \\
\hline \multirow[t]{2}{*}{ Avg. turnover (1946-2008) } & $-0.001 *$ & $-0.003 * * *$ & $0.002 * * *$ & $-0.002 * * *$ \\
\hline & {$[0.000]$} & {$[0.000]$} & {$[0.000]$} & {$[0.000]$} \\
\hline \multirow[t]{2}{*}{ School mark-Test Score ${ }^{a}$} & - & - & -0.001 & $0.008 * * *$ \\
\hline & & & {$[0.002]$} & {$[0.001]$} \\
\hline \multirow[t]{2}{*}{ Monitored Class } & - & - & $-0.015 * * *$ & $-0.007 * * *$ \\
\hline & & & {$[0.005]$} & {$[0.002]$} \\
\hline \multirow[t]{2}{*}{ Monitored School } & - & - & -0.001 & -0.002 \\
\hline & & & {$[0.003]$} & {$[0.001]$} \\
\hline \multirow[t]{2}{*}{ Ethnic Fractionalization } & - & - & $-0.218 * * *$ & $-0.035 * * *$ \\
\hline & & & [0.009] & {$[0.004]$} \\
\hline \multirow[t]{2}{*}{ ESCS Fractionalization } & - & - & $-0.148 * * *$ & $-0.030 * * *$ \\
\hline & & & {$[0.008]$} & [0.004] \\
\hline Municipality characteristics & \multicolumn{2}{|c|}{ NO } & \multicolumn{2}{|c|}{ YES } \\
\hline BP test of independence of residuals & \multicolumn{2}{|c|}{$\operatorname{Pr}=0.000$} & \multicolumn{2}{|c|}{$\operatorname{Pr}=0.000$} \\
\hline Test b1 (ita)=b1 (math) & \multicolumn{2}{|c|}{$\operatorname{Pr}=0.000$} & \multicolumn{2}{|c|}{$\operatorname{Pr}=0.000$} \\
\hline R squared & 0.000 & 0.021 & 0.066 & 0.035 \\
\hline Observations $^{b}$ & \multicolumn{2}{|c|}{26,663} & \multicolumn{2}{|c|}{24,801} \\
\hline
\end{tabular}

Regressions weighted by the number of students in the class. Standard errors clustered at the municipal level

${ }^{a}$ Difference between standardized school mark and predicted test score

${ }^{b}$ The unit of observation is the class 
Table 4: Cheating and Social Capital - 2nd graders

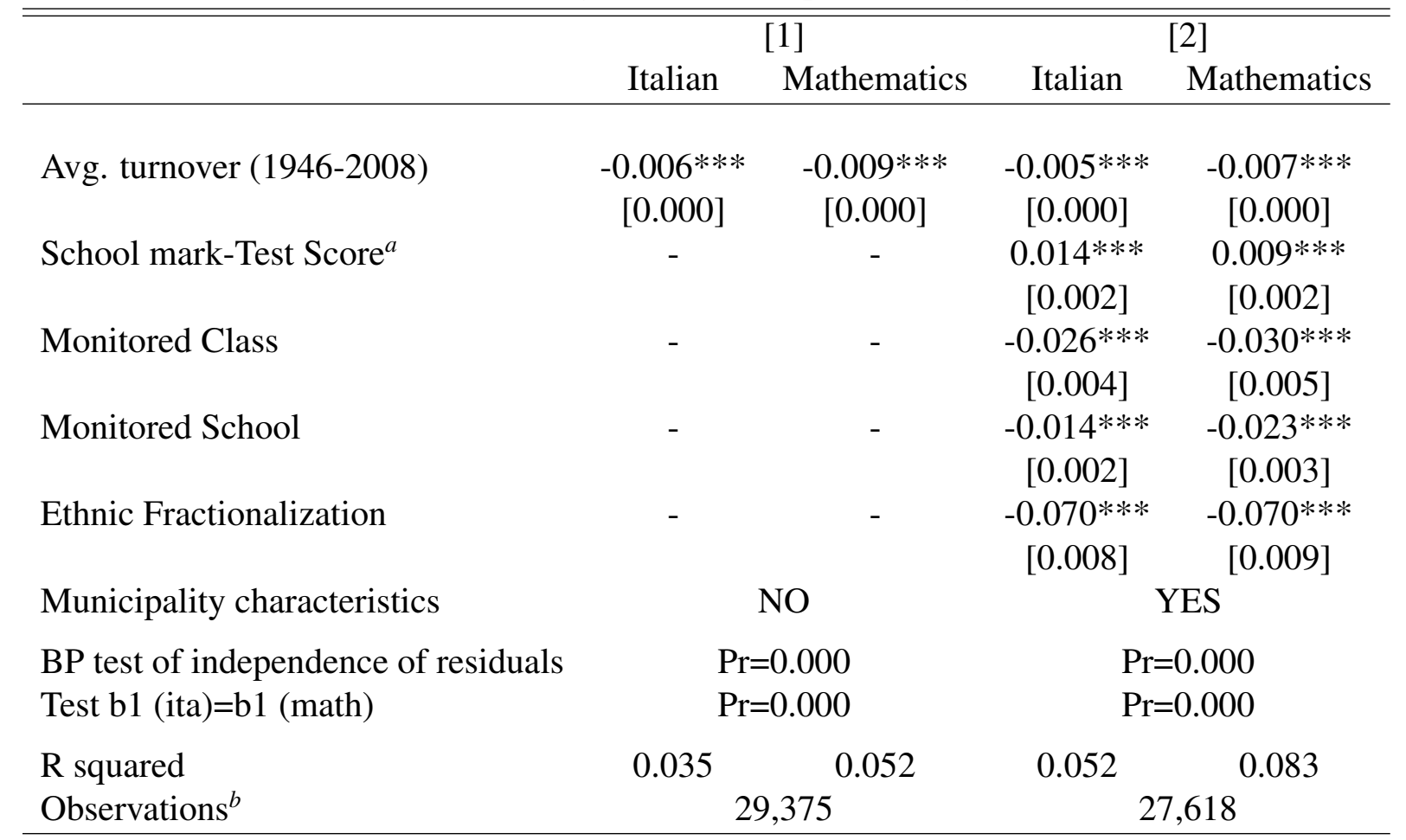

Regressions weighted by the number of students in the class. Standard errors clustered at the municipal level

${ }^{a}$ Difference between standardized school marks and predicted test score

${ }^{b}$ The unit of observation is the class

Table 5: Cheating and Social Capital - 8th graders

\begin{tabular}{|c|c|c|c|c|}
\hline & \multicolumn{2}{|c|}{ [1] } & \multicolumn{2}{|c|}{$[2]$} \\
\hline & Italian & Mathematics & Italian & Mathematics \\
\hline Avg. turnover (1946-2008) & $\begin{array}{c}-0.005 * * * \\
{[0.000]}\end{array}$ & $\begin{array}{c}-0.008 * * * \\
{[0.000]}\end{array}$ & $\begin{array}{c}-0.003 * * * \\
{[0.000]}\end{array}$ & $\begin{array}{c}-0.006^{* * *} * \\
{[0.000]}\end{array}$ \\
\hline Monitored Class & - & - & $\begin{array}{c}-0.016 * * * \\
{[0.005]}\end{array}$ & $\begin{array}{c}-0.011^{* *} \\
{[0.005]}\end{array}$ \\
\hline Ethnic Fractionalization & - & - & $\begin{array}{c}-0.037 * * \\
{[0.019]}\end{array}$ & $\begin{array}{c}-0.090 * * * \\
{[0.012]}\end{array}$ \\
\hline Municipality characteristics & \multicolumn{2}{|c|}{ NO } & \multicolumn{2}{|c|}{ YES } \\
\hline $\begin{array}{l}\text { BP test of independence of residuals } \\
\text { Test b1 (ita)=b1 (math) }\end{array}$ & \multicolumn{2}{|c|}{$\operatorname{Pr}=0.000$} & \multicolumn{2}{|c|}{$\operatorname{Pr}=0.000$} \\
\hline $\mathrm{R}$ squared & 0.022 & 0.064 & 0.042 & 0.087 \\
\hline Observations $^{a}$ & \multicolumn{2}{|c|}{26,244} & \multicolumn{2}{|c|}{26,197} \\
\hline
\end{tabular}

Regressions weighted by the number of students in the class. Standard errors clustered at the municipal level

${ }^{a}$ The unit of observation is the class 


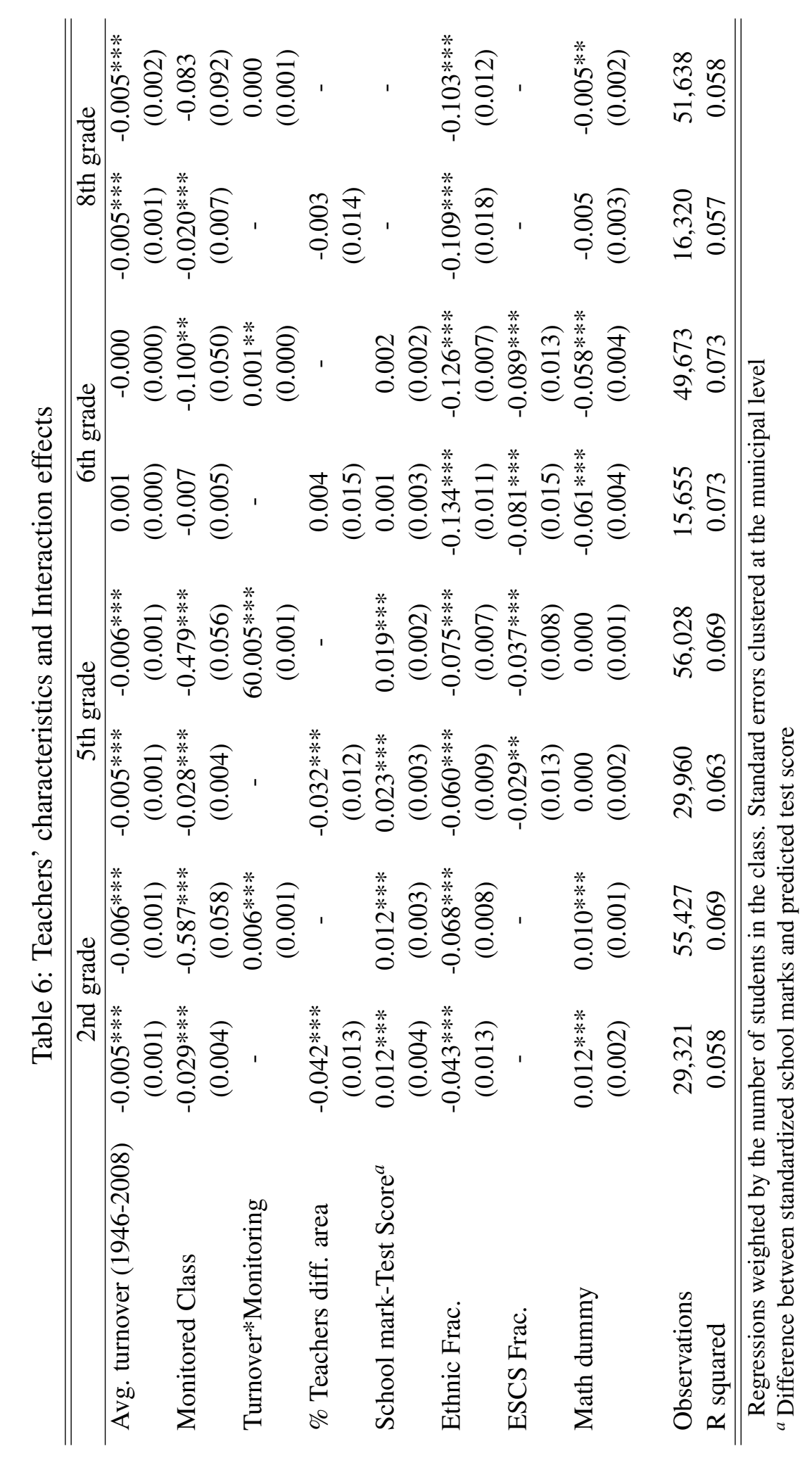


Table 7: Alternative measures of Social Capital (5th graders)

\begin{tabular}{|c|c|c|c|c|c|}
\hline & Turnover & $\begin{array}{l}\text { Turnover } \\
\text { (referenda) }\end{array}$ & $\begin{array}{l}\text { Turnover } \\
\text { (divorzio) }\end{array}$ & $\begin{array}{c}\text { Blood } \\
\text { Donations }\end{array}$ & $\begin{array}{c}\text { Trust } \\
\text { (WVS) }\end{array}$ \\
\hline \multirow[t]{2}{*}{ Social Capital } & $-0.004 * * *$ & $-0.578 * * *$ & $-0.722 * * *$ & $-0.924 * * *$ & $-0.097 * * *$ \\
\hline & {$[0.001]$} & {$[0.115]$} & {$[0.112]$} & {$[0.346]$} & {$[0.026]$} \\
\hline \multirow[t]{2}{*}{ Mathematics } & -0.000 & 0.000 & 0.000 & 0.001 & 0.000 \\
\hline & {$[0.002]$} & {$[0.002]$} & [0.002] & {$[0.002]$} & {$[0.002]$} \\
\hline \multirow[t]{2}{*}{ School mark-Test Score ${ }^{a}$} & $0.020 * * *$ & $0.020 * * *$ & $0.022 * * *$ & $0.022 * * *$ & $0.023 * * *$ \\
\hline & {$[0.003]$} & [0.004] & {$[0.004]$} & {$[0.003]$} & {$[0.003]$} \\
\hline \multirow[t]{2}{*}{ Monitored Class } & $-0.025 * * *$ & $-0.026^{* * *}$ & $-0.026 * * *$ & $-0.026 * * *$ & $-0.025 * * *$ \\
\hline & {$[0.004]$} & {$[0.004]$} & {$[0.004]$} & {$[0.004]$} & {$[0.005]$} \\
\hline \multirow[t]{2}{*}{ Ethnic Fractionalization } & $-0.056 * * *$ & $-0.040 * * *$ & $-0.045^{* * *}$ & $-0.055^{* * *}$ & $-0.061 * * *$ \\
\hline & {$[0.010]$} & {$[0.008]$} & {$[0.007]$} & [0.009] & {$[0.012]$} \\
\hline \multirow[t]{2}{*}{ ESCS Fractionalization } & $-0.032 * * *$ & $-0.029 * * *$ & $-0.030 * * *$ & $-0.034 * * *$ & $-0.034 * * *$ \\
\hline & {$[0.010]$} & {$[0.010]$} & {$[0.010]$} & {$[0.011]$} & {$[0.011]$} \\
\hline Province characteristics & YES & YES & YES & YES & YES \\
\hline Observations & 56,056 & 52,508 & 52,346 & 52,508 & 49,566 \\
\hline R squared & 0.074 & 0.082 & 0.085 & 0.072 & 0.072 \\
\hline
\end{tabular}

Regressions weighted by the number of students in the class. Standard errors clustered at the provincial level

${ }^{a}$ Difference between standardized school marks and predicted test score

Table 8: Universalistic and Particularistic Social Values (5th graders)

\begin{tabular}{lcccc}
\hline \hline & \multicolumn{2}{c}{ Participation } & \multicolumn{2}{c}{ Civic Awareness } \\
& Universalistic & Particularistic & Universalistic & Particularistic \\
\hline Social Capital & $-0.233^{* * *}$ & $0.053^{* * *}$ & $-0.218^{* * *}$ & $0.096^{* * *}$ \\
& $(0.079)$ & $(0.091)$ & $(0.063)$ & $(0.028)$ \\
School mark-Test Score & $a .027^{* * *}$ & $0.028^{* * *}$ & $0.029^{* * *}$ & $0.027^{* * *}$ \\
& $(0.005)$ & $(0.004)$ & $(0.005)$ & $(0.005)$ \\
Monitoring & $-0.025^{* * *}$ & $-0.025^{* * *}$ & $-0.025^{* * *}$ & $-0.026^{* * *}$ \\
& $(0.004)$ & $(0.004)$ & $(0.004)$ & $(0.004)$ \\
Ethnic frac. & $-0.074 * * *$ & $-0.077^{* * *}$ & $-0.072^{* * *}$ & $-0.068^{* * *}$ \\
& $(0.023)$ & $(0.026)$ & $(0.023)$ & $(0.024)$ \\
Observations & 52,508 & 52,508 & 52,508 & 52,508 \\
R-squared & 0.078 & 0.063 & 0.078 & 0.077 \\
\hline \hline
\end{tabular}

Regressions weighted by the number of students in the class. Standard errors clustered at the provincial level

${ }^{a}$ Difference between standardized school marks and predicted test score 